\title{
Numerical Solution Model of Brain Tumors Glioblastoma multiforme with Treatment Effect Using Runge Kutta Fehlberg Methods
}

\author{
Usman Pagalay ${ }^{1, *}$, Juhari ${ }^{2}$, Ahmad Syamsuadi ${ }^{3}$, Marwan Desky Ismansyah ${ }^{4}$ \\ ${ }^{1,2,4}$ Department of Mathematics, State Islamic University Maulana Malik Ibrahim Malang, Indonesia \\ ${ }^{2}$ Department of Mathematics, Muhammadiyah University of Makasar, Indonesia \\ ${ }^{*}$ Corresponding author.Email: usmanpagalay@yahoo.co.id
}

\begin{abstract}
The mathematical model of glioblastoma multiforme brain tumor (GBM) consists of a population of tumor cells that are sensitive $x(t)$ and the pupulation of cells susceptible to tumor $y(t)$. The effect of treatment on sensitive cells is given by Chemoresistant and pleotropic $\left(d_{1}\right)$, whereas the effect of treatment on susceptible cells is a precursor to prevention in tumor patients $\left(d_{2}\right)$. This article aims to solve the equation of GBM brain tumor model with the effect of treatment using Runge Kutta Fehlberg method. The result of Runge Kutta Fehlberg method has high accuracy and has fulfilled the given error tolerance of $10^{-7}$. Numerical solutions show that both populations have met the error tolerance when it reaches 200 days with $\Delta t=1$. Based on these results, the numerical solution to the effect of treatment using the Runge Kutta Fehlberg method has a good accuracy in solving nonlinear common differential equations of GBM brain tumor mode.
\end{abstract}

Keywords: Glioblastoma multiforme (GBM), treatment effect, numerical solution using Runge Kutta Fehlberg method.

\section{INTRODUCTION}

The mathematical model of glioblastoma multiforme brain tumor (GBM) consists of growth population of tumor-sensitive cells $x(t)$ and growth population of tumor cells $y(t)$. Bozkurt [1] explains the GBM brain tumor model as follows:

$$
\begin{aligned}
& \frac{d x(t)}{d t}=r_{1} x(t)( \\
& \left.R_{1}-\alpha_{1} x(t)-\alpha_{2} x([t-1])\right) \\
& \quad+p x(t)-\gamma_{1} x(t) y([t-1]) \\
& \quad-d_{1} x(t) x([t]) \\
& \begin{aligned}
\frac{d y(t)}{d t}=r_{2} y(t)( & \left.R_{2}-\beta_{1} y(t)-\beta_{2} y([t-1])\right) \\
& -d_{1} x(t) x([t])+\gamma_{1} x([t]) y(t)
\end{aligned}
\end{aligned}
$$

when $t \geq 0$

$$
x(-1)=x_{-1}, x(0)=x_{0}
$$

and

$$
y(-1)=y_{-1}, y(0)=y_{0}
$$

with $x_{-1}, x_{0}, y_{-1}$, dan $y_{0}$ is a constant real value and [.] is defined as a function of integers and $x_{-1} \neq 0, x_{0} \neq 0$.

The growth population of tumor cells $x(t)$ grew with a tumor growth rate $\left(r_{1}\right)$ of 1.08 cells / day and suppressed by a treatment rate $\left(d_{1}\right)$ of 0.6 cells/day. Treatment effect $d_{-} 1$ is a complex phenomenon using Chemoresistant with one treatment or using pleotropic resistance with multiple treatments. The population of sensitive cells $x(t)$ uses $x([t])$ and $x([t-1])$ which is constant in value with the population capacity $\left(R_{1}\right)$ of $4,704 \mathrm{cells} / \mathrm{ml} /$ day. The lower threshold $\left(\alpha_{1}\right)$ and the upper threshold $\left(\alpha_{2}\right)$ population rate of sensitive cells are 0,51 and 0,555 cells $/ \mathrm{ml} /$ day. The mutation rate $\left(\gamma_{1}\right)$ of sensitive cells $x(t)$ becomes susceptible cells $y(t)$ of 0.01 cells/day and is affected by the rate of cleavage of tumor cells $(p)$ of 0.192 cells/day [1].

Furthermore, in the growth population cells susceptible to tumor $y(t)$ grow with a tumor growth rate $\left(r_{2}\right)$ of 1.1664 cells/day and suppressed by the 
treatment rate $\left(d_{2}\right)$ of 0.006 cells/day. Treatment effects $d_{2}$ is a preliminary procedure of treatment or early steps of prevention in the healing of brain tumor patients. Population of susceptible cells using $y([t])$ and $y([t-$ 1]) with population capacity $\left(R_{2}\right)$ of 1,232 cells $/ \mathrm{ml} /$ day. The lower threshold $\left(\beta_{1}\right)$ and upper threshold $\left(\beta_{2}\right)$ population rate of susceptible cells are 1,5 and $0,2 \mathrm{cell} / \mathrm{ml} / \mathrm{day}$. There is a rate of change of susceptible cells $y(t)$ into sensitive cells $x(t)$ of $\gamma_{1}$ [1].

It is known that the exact solution with reference to the settlement [2] on logistical problems is obtained:

$$
\begin{gathered}
x(t)=x(t) e^{\left(\left(p+r_{1} R_{1}\right)-d_{1} x([t])-\alpha_{2} r_{1} x([t-1])-\gamma_{1} y([t-1])\right) t}(1 \\
\left.\quad-\beta_{1} r_{2} y(t)\left(\frac{e^{\left(\left(p+r_{1} R_{1}\right)-d_{1} x([t])-\alpha_{2} r_{1} x([t-1])-\gamma_{1} y([t-1])\right) t}-1}{\left(p+r_{1} R_{1}\right)-d_{1} x([t])-\alpha_{2} r_{1} x([t-1])-\gamma_{1} y([t-1])}\right)\right)^{-1} \\
\begin{array}{r}
y(t)=y(t) e^{\left\{\left(p+r_{1} R_{1}\right)-d_{1} x(t)-\alpha_{2} r_{1} x(t-1)-\gamma_{1} y(t-1)\right\} t}(1 \\
\left.-\beta_{1} r_{2} y(t)\left(\frac{e^{\left\{r_{2} R_{2}-\beta_{2} r_{2} y(t-1)+\gamma_{1} x(t)-d_{2} y(t)\right\} t}-1}{r_{2} R_{2}-\beta_{2} r_{2} y(t-1)+\gamma_{1} x(t)-d_{2} y(t)}\right)\right)^{-1}
\end{array}
\end{gathered}
$$

with,

$$
\begin{gathered}
\left(p+r_{1} R_{1}\right)-d_{1} x([t])-\alpha_{2} r_{1} x([t-1]) \\
-\gamma_{1} y([t-1]) \neq 0 \\
r_{2} R_{2}-\beta_{2} r_{2} y(t-1)+\gamma_{1} x(t)-d_{2} y(t) \neq 0
\end{gathered}
$$

\section{THEORITICAL REVIEW}

\subsection{System of Nonlinear Differential Equations Depends on Time}

The System of Nonlinear Differential Equations Depends on Time The ordinary differential equation is a differential equation containing the derivatives of the dependent variable on one independent variable. Ordinary differential equations of the form $F\left(t, y, \dot{y}, \ddot{y}, \ldots, \dot{y}^{n}\right)=$ 0 are said to be linear if $\mathrm{F}$ is linear in the variables 1 $t, y, \dot{y}, \ddot{y}, \ldots, \dot{y}^{n}[3]$. In general linear differential equations can be given as follows:

$$
a_{n}(x) y^{n}+a_{n-1}(x) y^{n-1}+\cdots+a_{1}(x) \dot{y}+a_{0}(x) y=f(x)
$$

Equation (1) is the n-order differential equation is said to be linear if it has the following characteristics: a. The dependent variable and its derivative are only one degree.

b. There is no multiplication between the dependent variable and its derivative.

c. The dependent variable is not a transcendent function.

\subsection{Runge Kutta Fehlberg Method}

According to [4] the Runge Kutta Fehlberg method is the fifth-order Runge Kutta method which has six function evaluations and can achieve accurate accuracy by yielding almost a value close to the analytical settlement value. The general formula of the Fifth Order Runge Kutta method is as follows:

$$
y_{i+1}=y_{i}+\sum_{j=1}^{6} b_{j} k_{j}
$$

with $j=1,2,3, \ldots, 6 ; b_{j}$ is a constant and $k_{j}$ is an evaluation function obtained from:

$$
\begin{gathered}
k_{j}=\Delta x f\left(x_{i}+c_{m} \Delta x y_{i}+a_{m 1} k_{1}+a_{m 2} k_{2}+\cdots\right. \\
\left.+a_{m m} k_{m}\right)
\end{gathered}
$$

$\Delta x$ is a step size expressed by $\Delta x=x_{i+1}-x_{i}$ while $c_{m}$ and $a_{m r}$ are constants with:

$$
c_{m}=\sum_{r=0}^{m} a_{m r}
$$


Furthermore, the method of Runge Kutta Fehlberg [5] is formulated as follows:

$$
\begin{gathered}
y_{i+1}=y_{i}+\frac{16}{135} k_{1}+\frac{6656}{12825} k_{3}+\frac{28561}{56430} k_{4}-\frac{9}{50} k_{5} \\
+\frac{2}{55} k_{6}
\end{gathered}
$$

with

$$
\begin{aligned}
& k_{1}=\Delta x f\left(x_{i}, y_{i}\right) \\
& k_{2}=\Delta x f\left(x_{i}+\frac{1}{4} \Delta x, y_{i}+\frac{1}{4} k_{1}\right) \\
& k_{3}=\Delta x f\left(x_{i}+\frac{3}{8} \Delta x, y_{i}+\frac{3}{32} k_{1}+\frac{9}{32} k_{2}\right) \\
& k_{4}=\Delta x f\left(x_{i}+\frac{12}{13} \Delta x, y_{i}+\frac{1932}{2197} k_{1}-\frac{7200}{2197} k_{2} \frac{d x(t)}{d t}=\right. \\
&\left.\quad+\frac{7296}{2197} k_{3}\right) \\
&\left.\quad-\frac{845}{4104} k_{4}\right) \\
& k_{5}=\Delta x f\left(x_{i}+\Delta x, y_{i}+\frac{439}{216} k_{1}-8 k_{2}+\frac{3680}{513} k_{3}\right. \\
&\left.\quad+\frac{1}{2} \Delta x, y_{i}-\frac{8}{27} k_{1}+2 k_{2}-\frac{3544}{2565} k \frac{1859}{4104} k_{4}-\frac{11}{40} k_{5}\right) \\
& k_{6}=\Delta x f\left(x_{i}\right)
\end{aligned}
$$

\subsection{Error}

In numerical methods always used value almost to find a solution that approximates the original solution or can be called a numerical solution. This is the value that causes errors. Errors occur for several reasons:
a. From observation
b. From ignoring something
c. From the tool used
c. From the numerical method used Error defined as:

$$
\varepsilon=\left|x-x_{t+1}\right|
$$

Where $(\varepsilon)$ represents the magnitude of error obtained from the result of almost to the true value. $x$ is a true value and $x_{t+1}$ is an approximation value. The error tolerance is the value of error given so that the value of almost numerical value will be as close as possible to the original value and formulated as:

$$
\left|x-x_{t+1}\right|<\delta
$$

for $\delta<0[6]$.

\section{DISCUSSION}

As follows in equation (1) it appears that the equation is a nonlinear equation shown by $\alpha_{1} r_{1} x(t)^{2}$ dan $\beta_{1} r_{2} y(t)^{2}$ [7]. Equation (1) can then be modified into logistic equations as follows:

$\left(\left(p+r_{1} R_{1}\right)-d_{1} x([t])-\alpha_{2} r_{1} x([t-1])\right.$
$\left.-\gamma_{1} y([t-1])\right) x(t)$

$(1$

$\left.-\frac{\alpha_{1} r_{1} x(t)}{\left(p+r_{1} R_{1}\right)-d_{1} x([t])-\alpha_{2} r_{1} x([t-1])-\gamma_{1} y([t-1])}\right)$

$$
\left(1-\frac{\beta_{1} r_{2} y(t)}{r_{2} R_{2}-\beta_{2} r_{2} y([t-1])+\gamma_{1} x([t-1])-d_{2} y([t])}\right)
$$

\subsection{Settlement of GBM Brain Tumor Equation Model}

3.1.1. Brain Tumor GBM with treatment effect $\left(d_{1}\right)$ and $\left(d_{2}\right)$

The differential equations of GBM equations ( $3 a)$ and $(3 \mathrm{~b})$ with treatment effects $\left(d_{1}\right)$ and $\left(d_{2}\right)$ at interval $t \in[0,200]$ with initial value $x(0)=x_{0}$ and step size $\Delta t=1$, then obtained for $n=1, x_{0}=0, x_{1}=$ 0,35 , and $y_{0}=0$ as follows:

$$
\begin{aligned}
k_{1}= & \left((0,192+0,08 \cdot 4,704)-0,6 x_{1}-0,555 \cdot 0,08 x_{0}-0,01 y_{0}\right) x_{1} \\
& \left(1-\frac{0,51 \cdot 0,08 x_{1}}{(0,192+0,08 \cdot 4,704)-0,6 x_{1}-0,555 \cdot 0,08 x_{0}-0,01 y_{0}}\right) \\
=\quad & 0.120414
\end{aligned}
$$




$$
\begin{aligned}
& k_{2}=\left((0,192+0,08 \cdot 4,704)-0,6 x_{1}-0,555 \cdot 0,08 x_{0}-0,01 y_{0}\right) \\
& \left(x_{1}+\frac{k_{1}}{4}\right)\left(1-\frac{0,51 \cdot 0,08\left(x_{1}+\frac{k_{1}}{4}\right)}{(0,192+0,08 \cdot 4,704)-0,6 x_{1}-0,555 \cdot 0,08 x_{0}-0,01 y_{0}}\right) \\
& =0.13030395635494 \\
& k_{3}=\left((0,192+0,08 \cdot 4,704)-0,6 x_{1}-0,555 \cdot 0,08 x_{0}-0,01 y_{0}\right) \\
& \left(x_{1}+\left(\left(\frac{3}{32}\right) k_{1}+\left(\frac{9}{32}\right) k_{2}\right)\right) \\
& \left(1-\frac{0,51 \cdot 0,08\left(x_{1}+\left(\left(\frac{3}{32}\right) k_{1}+\left(\frac{9}{32}\right) k_{2}\right)\right)}{(0,192+0,08 \cdot 4,704)-0,6 x_{1}-0,555 \cdot 0,08 x_{0}-0,01 y_{0}}\right) \\
& =0.136127883420054 \\
& k_{4}=\left((0,192+0,08 \cdot 4,704)-0,6 x_{1}-0,555 \cdot 0,08 x_{0}-0,01 y_{0}\right) \\
& \left(x_{1}+\left(\left(\frac{1932}{2197}\right) k_{1}-\left(\frac{7200}{2197}\right) k_{2}+\left(\frac{7296}{2197}\right) k_{3}\right)\right) \\
& \left(1-\frac{0,51 \cdot 0,08\left(x_{1}+\left(\left(\frac{1932}{2197}\right) k_{1}-\left(\frac{7200}{2197}\right) k_{2}+\left(\frac{7296}{2197}\right) k_{3}\right)\right)}{(0,192+0,08 \cdot 4,704)-0,6 x_{1}-0,555 \cdot 0,08 x_{0}-0,01 y_{0}}\right) \\
& =0.162888195593675 \\
& k_{5}=\left((0,192+0,08 \cdot 4,704)-0,6 x_{1}-0,555 \cdot 0,08 x_{0}-0,01 y_{0}\right) \\
& \left(x_{1}+\left(\left(\frac{439}{216}\right) k_{1}-8 k_{2}+\left(\frac{3680}{513}\right) k_{3}-\left(\frac{845}{4104}\right) k_{4}\right)\right) \\
& \left(1-\frac{0,51 \cdot 0,08\left(x_{1}+\left(\left(\frac{439}{216}\right) k_{1}-8 k_{2}+\left(\frac{3680}{513}\right) k_{3}-\left(\frac{845}{4104}\right) k_{4}\right)\right)}{(0,192+0,08 \cdot 4,704)-0,6 x_{1}-0,555 \cdot 0,08 x_{0}-0,01 y_{0}}\right) \\
& =0.167457989232798 \\
& k_{6}=\left((0,192+0,08 \cdot 4,704)-0,6 x_{1}-0,555 \cdot 0,08 x_{0}-0,01 y_{0}\right) \\
& \left(x_{1}-\left(\left(\frac{8}{27}\right) k_{1}-\left(2 k_{2}\right)+\left(\frac{3544}{2565}\right) k_{3}-\left(\frac{1859}{4104}\right) k_{4}+\left(\frac{11}{40}\right) k_{5}\right)\right)
\end{aligned}
$$




$$
\begin{aligned}
& \left(1-\frac{0,51 \cdot 0,08\left(x_{1}-\left(\left(\frac{8}{27}\right) k_{1}-\left(2 k_{2}\right)+\left(\frac{3544}{2565}\right) k_{3}-\left(\frac{1859}{4104}\right) k_{4}+\left(\frac{11}{40}\right) k_{5}\right)\right)}{(0,192+0,08 \cdot 4,704)-0,6 x_{1}-0,555 \cdot 0,08 x_{0}-0,01 y_{0}}\right) \\
& =0.141539080962147
\end{aligned}
$$

So the $x_{2}$ value of the equation for $\Delta t=1$ is:

$$
\begin{aligned}
x_{2} & =x_{1}+\left(\left(\frac{16}{135}\right) k_{1}+\left(\frac{6656}{12825}\right) k_{3}+\left(\frac{28561}{56430}\right) k_{4}-\left(\frac{9}{50}\right) k_{5}+\left(\frac{2}{55}\right) k_{6}\right)(1) \\
& =0.492368760703149
\end{aligned}
$$

Next, for $t=1, x_{1}=0.35, y_{1}=0.25$, and $y_{0}=0$ is:

$$
\begin{aligned}
& k_{1}=\left(0.10348-0.0168 y_{0}+0.01 x_{1}-0.06 y_{1}\right) y_{1} \\
& \left(1-\frac{0.126 y_{1}}{\left(0.10348-0.0168 y_{0}+0.01 x_{1}-0.06 y_{1}\right)}\right) \\
& =0.0255845 \\
& k_{2}=\left(0.10348-0.0168 y_{0}+0.01 x_{1}-0.06 y_{1}\right)\left(y_{1}+\frac{k_{1}}{4}\right) \\
& \left(1-\frac{0.126\left(y_{1}+\frac{k_{1}}{4}\right)}{\left(0.10348-0.0168 y_{0}+0.01 x_{1}-0.06 y_{1}\right)}\right) \\
& =0.026218403375271 \\
& k_{3}=\left(0.10348-0.0168 y_{0}+0.01 x_{1}-0.06 y_{1}\right)\left(y_{1}+\left(\left(\frac{3}{32}\right) k_{1}+\left(\frac{9}{32}\right) k_{2}\right)\right) \\
& \left(1-\frac{0.126\left(y_{1}+\left(\left(\frac{3}{32}\right) k_{1}+\left(\frac{9}{32}\right) k_{2}\right)\right)}{\left(0.10348-0.0168 y_{0}+0.01 x_{1}-0.06 y_{1}\right)}\right) \\
& =0.02655260871906 \\
& k_{4}=\left(0.10348-0.0168 y_{0}+0.01 x_{1}-0.06 y_{1}\right)\left(y_{1}+\left(\left(\frac{3}{32}\right) k_{1}+\left(\frac{9}{32}\right) k_{2}\right)\right) \\
& \left(1-\frac{0.126\left(y_{1}+\left(\left(\frac{3}{32}\right) k_{1}+\left(\frac{9}{32}\right) k_{2}\right)\right)}{\left(0.10348-0.0168 y_{0}+0.01 x_{1}-0.06 y_{1}\right)}\right) \\
& =0.028032080984403 \\
& k_{5}=\left(0.10348-0.0168 y_{0}+0.01 x_{1}-0.06 y_{1}\right) \\
& \left(y_{1}+\left(\left(\frac{1932}{2197}\right) k_{1}-\left(\frac{7200}{2197}\right) k_{2}+\left(\frac{7296}{2197}\right) k_{3}\right)\right)
\end{aligned}
$$




$$
\begin{aligned}
&\left(1-\frac{0.126\left(y_{1}+\left(\left(\frac{1932}{2197}\right) k_{1}-\left(\frac{7200}{2197}\right) k_{2}+\left(\frac{7296}{2197}\right) k_{3}\right)\right)}{\left(0.10348-0.0168 y_{0}+0.01 x_{1}-0.06 y_{1}\right)}\right) \\
&= 0.028248863331640 \\
& k_{6}=\left(0.10348-0.0168 y_{0}+0.01 x_{1}-0.06 y_{1}\right) \\
&\left(y_{1}-\left(\left(\frac{8}{27}\right) k_{1}-\left(2 k_{2}\right)+\left(\frac{3544}{2565}\right) k_{3}-\left(\frac{1859}{4104}\right) k_{4}+\left(\frac{11}{40}\right) k_{5}\right)\right) \\
&=\left(\begin{array}{l}
0.126\left(y_{1}-\left(\left(\frac{8}{27}\right) k_{1}-\left(2 k_{2}\right)+\left(\frac{3544}{2565}\right) k_{3}-\left(\frac{1859}{4104}\right) k_{4}+\left(\frac{11}{40}\right) k_{5}\right)\right) \\
\left(1-\frac{\left.0.10348-0.0168 y_{0}+0.01 x_{1}-0.06 y_{1}\right)}{0}\right)
\end{array}\right) \\
& 0.026881545429889
\end{aligned}
$$

So the $y_{2}$ value of the equation for $\Delta t=1$ is:

$$
\begin{aligned}
y_{2} & =y_{1}+\left(\left(\frac{16}{135}\right) k_{1}+\left(\frac{6656}{12825}\right) k_{3}+\left(\frac{28561}{56430}\right) k_{4}-\left(\frac{9}{50}\right) k_{5}+\left(\frac{2}{55}\right) k_{6}\right)(1) \\
& =0.276893316111701
\end{aligned}
$$

The results of numerical solutions, exact solutions, and errors ( $\varepsilon$ ) for equations (3a) and (3b) are given in Table 1.

Table 1. Numerical solutions, exact solutions, and error at equations (3a) and (3b) with treatment effects $\left(d_{1}\right)$ and $\left(d_{2}\right)$

\begin{tabular}{lcccccc}
\multicolumn{1}{c}{$t$} & \multicolumn{2}{c}{ Runge Kutta Fehlberg Method } & \multicolumn{2}{c}{ Exact Solution } & \multicolumn{2}{c}{ Error } \\
& $x_{t+1}$ & $y_{t+1}$ & $x(t)$ & $y(t)$ & $\left|x_{t+1}-x(t)\right|$ & $\left|y_{t+1}-y(t)\right|$ \\
$t=0$ & 0.35 & 0.25 & 0.35 & 0.25 & 0 & 0 \\
$t$ & 0.785769918 & 3.0356904749 & 0.7857699188 & 3.0356904541 & $0.0000000004 z$ & 0.0000000208526 \\
$=50$ & 4338 & 925 & 538 & 396 & & \\
$t$ & 0.783531895 & 3.1444950346 & 0.7835318957 & 3.1444950345 & $0.0000000000(0.0000000000509$ \\
$=100$ & 7545 & 134 & 556 & 625 & & 0.0000000000001 \\
$t=$ & 0.783527079 & 3.1447246942 & 0.7835270798 & 3.1447246942 & $10^{-13}$ & \\
150 & 8256 & 812 & 256 & 811 & & $10^{-13}$ \\
$t$ & 0.783527070 & 3.1447251600 & 0.7835270700 & 3.1447251600 & $10^{-13}$ &
\end{tabular}

Simulation of GBM brain tumor model with the treatment effect given was for $t \in[0,200]$ and the susceptible tumor cell cells $x(t)$ and $y(t)$ were as follows: 


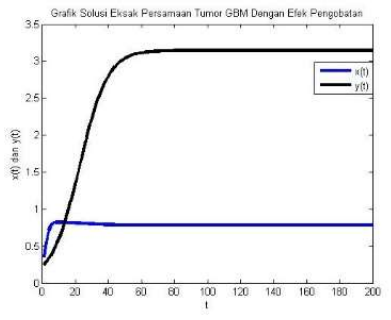

(a)

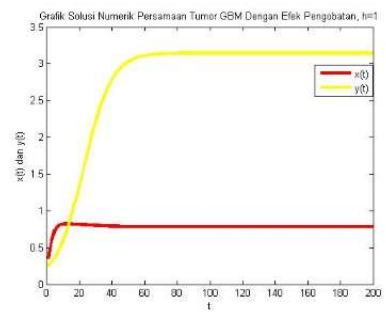

(b)
Figure 1. (a) Exsact Solution of Brain Tumor GBM (b) Numerical Solution of Brain Tumor GBM

Figure 1 (a) explains the growth graph of tumor cells sensitive $x(t)$ from the large error of tolerance given by $\delta=10^{-7}$ it is found that the equation of tumor cells that are sensitive $x(t)$ will be stable on day 141 to day 200 with large cells tumor is between 0,7835270999203 cells $/ \mathrm{ml}$ to 0,7835270705365 cells $/ \mathrm{ml}$.

In the growth of susceptible tumor cells $y(t)$, it is found that the growth of tumor cells susceptible $y(t)$ will be stable on day 167 to day 200 with large cells tumor is between 3,14472510434 cells $/ \mathrm{ml}$ up to $3.144725160081 \mathrm{cells} / \mathrm{ml}$.

Figure 1 (b) describes numerical rate movement in population growth of sensitive tumor cells $x(t)$ and susceptible cells $y(t)$ using Runge Kutta Fehlberg method at rate $\Delta t=1$ at $t \in[0,200]$. Furthermore, the error for equation problems (3a) and (3b) is given in the following Figure 2.

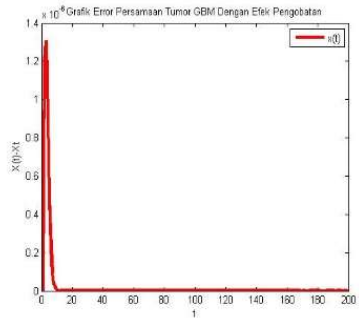

(a)

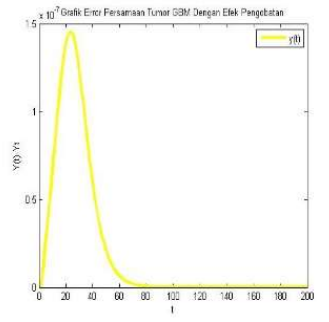

(b)
Figure 2. (a) Error Chart $\left|x_{t}-x(t)\right|$ depend on Time (b) Error Chart $r\left|y_{t}-y(t)\right|$ depend on Time

Figure 2 (b) describes the magnitude of error in the case of the growth of susceptible cells to tumor $y(t)$. Figure 2 (b) shows that from the given error of tolerance equal to $\delta=10^{-7}$ it is found that the equation of susceptible tumor cells $y(t)$ will be stable at the 34th iteration until the 200th iteration with the error rate being between 0,0000000976556 to $10^{-13}$.
A comparison of the exact solution and the numerical solution using the Runge Kutta Fehlberg equation is given in the following Figure:

The comparison between the exact solution and the numerical solution in Figure 3.2 explains that the solution approach by the Runge Kutta Fehlberg method can be used to approach the exact solution of equations (1) with error tolerance $\delta=10^{-7}$.

\subsubsection{Brain Tumor GBM without treatment effect $\left(d_{1}\right)$}

The results of numerical solutions, exact solutions, and errors $(\varepsilon)$ for equations (3a) and (3b) are when $d_{1}=$ 0 given in Table 2.

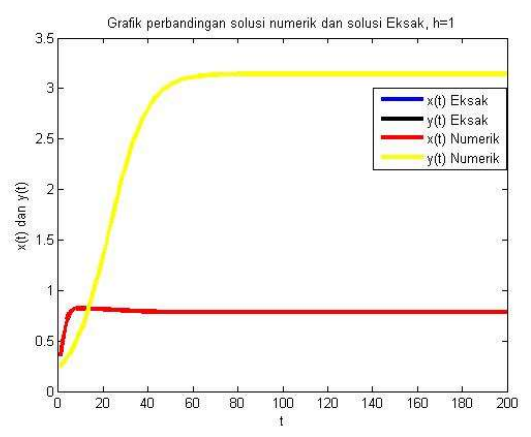

Figure 3. Comparison between the exact solution and the numerical solution chart

Simulation of GBM brain tumor model without the treatment effect $d_{1}$ given for $t \in[0,200]$ were as Figure 4.

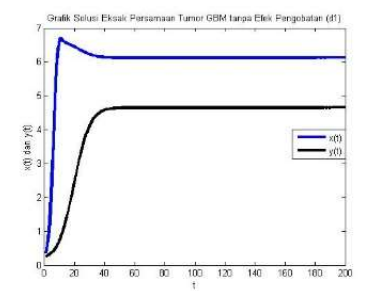

(a)

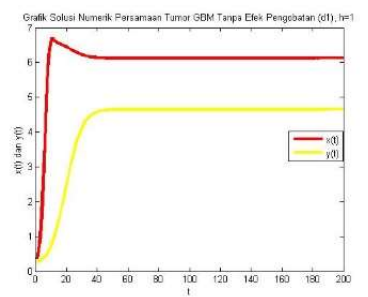

(b)
Figure 4. (a) Exact Solution of Brain Tumor GBM (b) Numerical Solution of Brain Tumor GBM 
Table 2. Numerical solutions, exact solutions, and error at equations (3a) and (3b) without treatment effects $\left(d_{1}\right)$

\begin{tabular}{|c|c|c|c|c|c|c|}
\hline \multirow{2}{*}{$t$} & \multicolumn{2}{|c|}{ Runge Kutta Fehlberg Method } & \multirow{2}{*}{$\begin{array}{l}\text { Exact Solution } \\
\qquad x(t)\end{array}$} & \multicolumn{3}{|c|}{ Error } \\
\hline & $x_{t+1}$ & $y_{t+1}$ & & $y(t)$ & $\left|x_{t+1}-x(t)\right|$ & $\left|y_{t+1}-y(t)\right|$ \\
\hline$t=0$ & 0.35 & 0.25 & 0.35 & 0.25 & 0 & 0 \\
\hline $\begin{array}{l}t \\
=50\end{array}$ & 6.1262809343562 & 4.6433032063880 & 6.1262809569039 & 4.6433031358394 & 0.000000000225477 & 0.000000000705486 \\
\hline $\begin{array}{l}t \\
=100\end{array}$ & 6.1242484819103 & 4.6534031735414 & 6.1242484819109 & 4.6534031735398 & 0.000000000000006 & 0.000000000000015 \\
\hline $\begin{array}{l}t= \\
150\end{array}$ & 6.1242484146771 & 4.6534035069593 & 6.1242484146771 & 4.6534035069593 & $10^{-13}$ & $10^{-13}$ \\
\hline$t$ & 6.1242484146748 & 4.6534035069703 & 6.1242484146748 & 4.6534035069703 & $10^{-13}$ & $10^{-13}$ \\
\hline
\end{tabular}

Figure 4 (a) explains the growth graph of tumor cells sensitive $x(t)$ without treatment effect $d_{1}$. From the large error of tolerance given by $\delta=10^{-7}$ it is found that the equation of tumor cells that are sensitive $x(t)$ will be stable on day 99 to day 200 with large cells tumor is between $6,1242484819109 \mathrm{sel} / \mathrm{ml}$ to $6,1242484146748 \mathrm{sel} / \mathrm{ml}$.

In the growth of susceptible tumor cells $y(t)$, it is found that the growth of tumor cells susceptible $y(t)$ will be stable on day 119 to day 200 with large cells tumor is between $4,6534035003691 \mathrm{sel} / \mathrm{ml}$ to $4,6534035069703 \mathrm{sel} / \mathrm{ml}$.

Figure 4 (b) describes numerical rate movement in population growth of sensitive tumor cells $x(t)$ without treatment effect $d_{1}$ and susceptible cells $y(t)$ using Runge Kutta Fehlberg method at rate $\Delta t=1$ at $t \in$ $[0,200]$. Furthermore, the error for equation problems $(3 a)$ and $(3 b)$ is given in the following Figure:

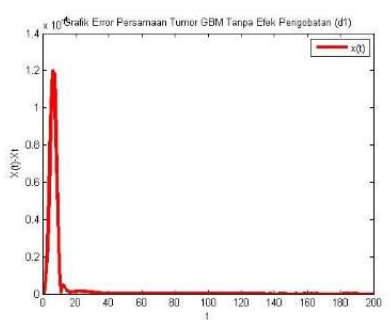

(a)

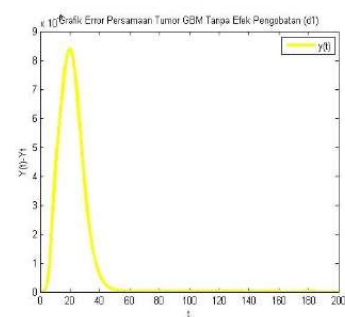

(b)
Figure 5. (a) Error Chart $\left|x_{t}-x(t)\right|$ depend on Time (b) Error Chart $r\left|y_{t}-y(t)\right|$ depend on Time

Figure 5 (a) describes the error in the case of growth of tumor cells that are sensitive $x(t)$ without $d_{1}$, it is found that the equation of sensitive tumor cells $x(t)$ will be stable at the 43th iteration until the 200th iteration with the error rate being between 0,0000000953660 to $10^{-13}$.

Figure 5 (b) describes the magnitude of error in the case of the growth of susceptible cells to tumor $y(t)$. Figure 3.5 (b) shows that from the given error of tolerance equal to $\delta=10^{-7}$ it is found that the equation of susceptible tumor cells $y(t)$ will be stable at the 49th iteration until the 200th iteration with the error rate being between 0,0000000872009 to $10^{-13}$.

A comparison of the exact solution and the numerical solution using the Runge Kutta Fehlberg equation is given in the figure 6 .

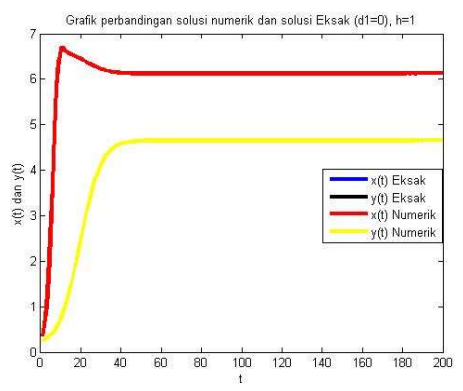

Figure 6. Comparison Between the Exact Solution and the Numerical Solution Chart

The comparison between the exact solution and the numerical solution in Figure 6 explains that the solution by using numerical method with error tolerance $\delta=$ $10^{-7}$. Show that the solution approach by the Runge Kutta Fehlberg method can be used to approach the exact solution of equations (1) without treatment efffect $d_{1}$ reach $10^{-13}$. 
Table 3. Numerical solutions, exact solutions, and error at equations (3a) and (3b) without treatment effects $\left(d_{1}\right)$

\begin{tabular}{|c|c|c|c|c|c|c|}
\hline \multirow{2}{*}{$t$} & \multicolumn{2}{|c|}{ Runge Kutta Fehlberg Method } & \multirow{2}{*}{$\begin{array}{l}\text { Exact Solution } \\
\qquad x(t)\end{array}$} & \multicolumn{3}{|c|}{ Error } \\
\hline & $x_{t+1}$ & $y_{t+1}$ & & $y(t)$ & $\left|x_{t+1}-x(t)\right|$ & $\left|y_{t+1}-y(t)\right|$ \\
\hline$t=0$ & 0.35 & 0.25 & 0.35 & 0.25 & 0 & 0 \\
\hline $\begin{array}{l}t \\
=50\end{array}$ & 0.7774610256746 & 3.6254604084358 & 0.7774610246428 & 3.6254604418472 & 0.0000000006682 & 0.0000000333886 \\
\hline $\begin{array}{l}t \\
=100\end{array}$ & 0.7742137000678 & 3.7830188641103 & 0.7742137000696 & 3.78301886402427 & 0.0000000000018 & 0.0000000000856 \\
\hline $\begin{array}{l}t= \\
150\end{array}$ & 0.7742070221669 & 3.7833351118168 & 0.7742070221669 & 3.7833351118116 & $10^{-13}$ & 0.0000000000002 \\
\hline $\begin{array}{l}t \\
=200\end{array}$ & 0.7742070094016 & 3.7833357163176 & 0.7742070094016 & 3.7833357163176 & $10^{-13}$ & $10^{-13}$ \\
\hline
\end{tabular}

\subsubsection{Brain Tumor GBM without Treatment Effect $\left(d_{2}\right)$}

The results of numerical solutions, exact solutions, and errors $(\varepsilon)$ for equations (3a) and (3b) are when $d_{2}=$ 0 given in the Table 3 .

Simulation of GBM brain tumor model without the treatment effect $d_{2}$ given for $t \in[0,200]$ were as shown in Figure 7.

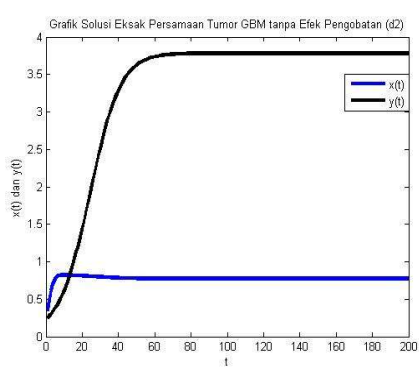

(a)

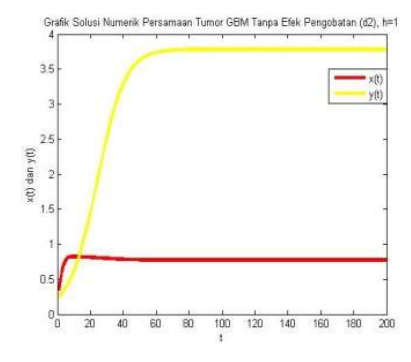

(b)
Figure 7. (a) Exsact Solution of Brain Tumor GBM (b) Numerical Solution of Brain Tumor GBM

Figure 7 (a) explains the growth graph of tumor cells sensitive $x(t)$ without treatment effect $d_{2}$. From the large error of tolerance given by $\delta=10^{-7}$ it is found that the equation of tumor cells that are sensitive $x(t)$ will be stable on day 135 to day 200 with large cells tumor is between $0,7742070930267 \mathrm{sel} / \mathrm{ml}$ to $0,7742070094016 \mathrm{sel} / \mathrm{ml}$.

In the growth of susceptible tumor cells $y(t)$, it is found that the growth of tumor cells susceptible $y(t)$ will be unstable to day 200 with large cells tumor is $3,7833357163176 \mathrm{sel} / \mathrm{ml}$.
Figure 4 (b) describes numerical rate movement in population growth of sensitive tumor cells $x(t)$ without treatment effect $d_{2}$ and susceptible cells $y(t)$ using Runge Kutta Fehlberg method at rate $\Delta t=1$ at $t \in$ $[0,200]$. Furthermore, the error for equation problems (3a) and ( $3 b)$ is given in the following Figure:

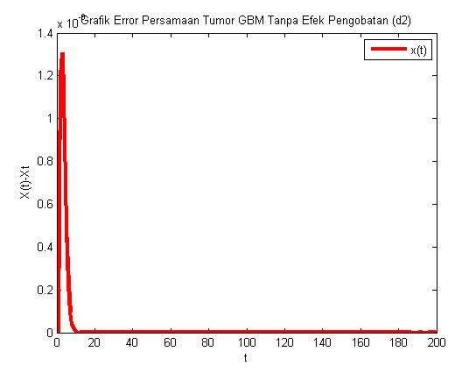

(a)

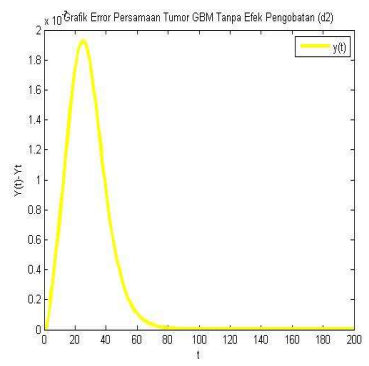

(b)
Figure 8. (a) Error Chart $\left|x_{t}-x(t)\right|$ depend on Time (b) Error Chart $r\left|y_{t}-y(t)\right|$ depend on Time

Figure 8 (a) describes the error in the case of growth of tumor cells that are sensitive $x(t)$, it is found that the equation of sensitive tumor cells $x(t)$ will be stable at the $7^{\text {th }}$ iteration until the 200th iteration with the error rate being between 0,0000000965519 to $10^{-13}$.

Figure 8 (b) describes the magnitude of error in the case of the growth of susceptible cells to tumor $y(t)$ without $d_{2}$. Figure 8 (b) shows that from the given error of tolerance equal to $\delta=10^{-7}$ it is found that the equation of susceptible tumor cells $y(t)$ will be stable at the $40^{\text {th }}$ iteration until the 200th iteration with the error rate being between 0,0000000918667 to $10^{-13}$.

A comparison of the exact solution and the numerical solution using the Runge Kutta Fehlberg equation is given in the following Figure 9. 


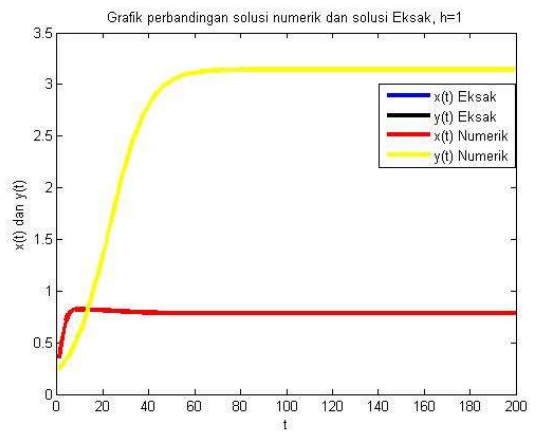

Figure 9. Comparison Between the Exact Solution and the Numerical Solution Chart

The comparison between the exact solution and the numerical solution in Figure 3.6 explains that the solution by using numerical method with error tolerance $\delta=10^{-7}$. Show that the solution approach by the Runge Kutta Fehlberg method can be used to approach the exact solution of equations (1) without treatment efffect $d_{2}$ reach $10^{-13}$.

\section{CONCLUSSION}

A numerical solution to the effect of treatment using the Runge Kutta Fehlberg method is used to describe numerical behavior in a nonlinear differential equation. The numerical resolution of the GBM brain tumor model results in an approach with a large error of $10^{-13}$ to the 200th day with $\Delta t=1$. The GBM brain tumor model that is affected by treatment and without the effect of treatment gives different results. That is, the effect of treatment $\left(d_{1}\right)$ and $\left(d_{2}\right)$ on patients affected by GBM brain tumor will have an impact on tumor growth rate.

\section{REFERENCES}

[1] F. Bozkurt, Mathematical Modeling and Stability Analysis of the Brain Tumor Glioblastoma Multiforme (GBM), International Journal of Modeling and Optimization, vol. 4, no. 4, pp. 257262, 2014.

[2] J. W. Bruce, Exact Solution For Fractional Logistic, Physica A: Statistical Mechanics and its Applications, 2015, pp. 103-108.

[3] S. B. Waluya, Persamaan Diferensial, Yogyakarta: Graha Ilmu, 2006.

[4] E. Kreyzig, Advanced Engineering Mathematics, New York: John Wiley \&Sons Inc, 2003.

[5] U. Pagalay and Muhlish, Numerical Solution for Immunology Tuberculosis Model Using Runge Kutta Fehlberg and Adams Bashforth Moulton Method, Jurnal Teknologi (Sains and Engineering), vol. 78, no. 5, pp. 369-372, 2016.

[6] S. D. Conte, Dasar-Dasar Analisis Numerik. Jakarta: Erlangga, 1993.

[7] J. E. Schmitz, A. R. Kansal, and S. Torquato, Acellular automaton model of brain tumor treatment and resistance, Journal of Theoretical Medicine, vol. 4, no. 4, pp.223-239, 2002. 